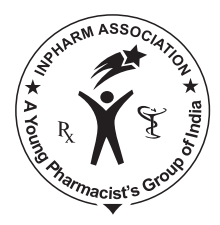

\title{
An Evaluation of Consumers' Perceptions Regarding “Modern Medicines" in Penang, Malaysia
}

\author{
Zaheer-Ud-Din Babar, Mohamed Azmi Ahmad Hassali', Tai Lee Shyong', \\ Tan Keat Hin', Chong Soon Cien', Lim Soo Bin', \\ Shamini Chanmal Anantham', Ranita Kirubakaran', Sia bee Ping1, \\ Chiew Shoen Chuen ${ }^{1}$, Jaswinder Kaur Sohan Singh ${ }^{1}$
}

\author{
Division of Pharmacy Practice, School of Pharmacy, Faculty of Medical and Health Sciences, \\ The University of Auckland, New Zealand, 'Discipline of Social and Administrative Pharmacy, \\ School of Pharmaceutical Sciences, Universiti Sains Malaysia, Penang, Malaysia
}

Address for correspondence: Dr. Zaheer-Ud-Din Babar; E-mail: z.babar@auckland.ac.nz

\begin{abstract}
The objective of this study was to evaluate consumers' perceptions regarding "modern medicines" in Penang, Malaysia. To conduct this exploratory study, qualitative techniques were used. Consumers more than 19 years of age and could speak English, who had visited a pharmacy in the last 30 days, were included from the four major areas of Penang. Eighteen interviews were conducted until the point of saturation. The interviews were audio-taped and then transcribed verbatim for thematic content analysis. Many consumers correctly identified the major characteristics and properties of modern medicines; however, others raised doubts regarding the safety, quality and efficacy of "modern medicines". There were many misconceptions such as "all modern medicines can cause dependence", traditional medicines are completely "free of side-effects" and "Western medicines cure while Chinese medicines don't". Color was also considered a strong determinant of the safety and characteristics of a medicine. Regarding consumers' "medicine information seeking behavior", many consumers would seek information from doctors and pharmacists; however, there were others, who would look for books, or get it from the internet and friends. Of concern many consumers emphasized that while "self-searching for drug information" they would only look for side-effects. Misconceptions regarding medicine-taking behavior, medicine use and compliance were also identified. Though several consumers complied with the medicine-taking instructions, many reported that they would stop taking medicines, once they feel better. Though many consumers correctly identified the characteristics of "modern medicines", misconceptions regarding "medicine information sources and "medicine-taking behavior" were rampant. The situation demands corrective actions including community-oriented educational campaigns to improve "medicine use" in the society.
\end{abstract}

Key words: Consumer perception, modern medicine, Malaysia, Penang, qualitative study

\begin{tabular}{|l|l|}
\hline \multicolumn{2}{|c|}{ Access this article online } \\
\hline Quick Response Code: & \\
\hline & Website: \\
\hline & www.jyoungpharm.in \\
& \\
\hline & DOI: \\
\hline
\end{tabular}

\section{INTRODUCTION}

Medicines are substances that are meant to cure illness or injury or to maintain the health of humans. Modern medicines are also called Western medicines, conventional medicines, mainstream medicines, orthodox medicines, and allopathic medicines. ${ }^{[1]}$ Modern medicines exclude 
traditional medicines, herbal medicines, supplements and recreational drugs.

Medicines are the main treatment modality globally and they have played a key role in alleviating human suffering. However, an important question remains unanswered, how do we define medicines? For healthcare professionals, they are "tools" to apply their skills as well as to advance their profession. For drug companies, they are commodities being manufactured, distributed, sold and marketed to consumers, and are a profitable business. But what are they for consumers and patients?

Finding an answer to this question is important because consumers' perception can influence their drug-taking behavior and in turn can affect "treatment outcomes". Previous studies have shown that consumers did not realize the "possible hazards" associated with the "modern medicines" and instead had a "positive image" with the view that medicines should be used in the event of any sickness. ${ }^{[2]}$ On the other hand an "increasingly negative image" about medicines can also affect peoples' adherence, such that minimizing misunderstandings is also "vital" and can contribute to improving concordance. ${ }^{[3]}$

Therefore, it is also pertinent to learn the public's sources of drug information as well as their perception regarding the color, safety, and efficacy of medicines. Color of medicines has also been found to be associated with beliefs and practices; white drugs were associated with pain relief, red for building blood, blue to aid sleep, and yellow for malaria treatment in a study in Nigeria. ${ }^{[4]}$

Medical treatment in Malaysia depends heavily on pharmaceuticals and in the recent past due to higher per capita income, drug use has increased steadily. The Malaysian government's drug expenditure rose from RM 200 million ( 1 US $\$=3.35$ RM - Ringgit Malaysia approx) in 1994 to RM 1.12 billion in 2005. In 2005, it was estimated that RM 1.13 billion has been spent on purchasing pharmaceuticals in the private sector. ${ }^{[5]}$ The rise in drug expenses could be an indicator of the high drug utilization, drawing renewed attention and interest towards the issues of "medicine use" in the community.

Though the use of medicines has increased manifold data describing how people perceive modern medicines is scarce. Studies on the issue could be very helpful to improve compliance, concordance and therapeutic outcome as well as build appropriate medicine use policies in the country. The findings of the study can also help healthcare professionals to understand their communities better as well as build effective public health interventions.

\section{MATERIALS AND METHODS}

A qualitative technique was used to conduct this exploratory study and to get an in-depth understanding of the issue. ${ }^{[6]}$ The inclusion criteria were consumers who were more than 19 years of age living in the four diverse geographical areas in the state of Penang, who had visited a community pharmacy at least once in the last 30 days, and were able to speak English. Health professionals, medical students and people working in the medical field/drug industry were excluded from the study. A "purposive sampling technique" was used to include a diverse group in terms of age groups, race, and areas of residence. All participants were clearly explained the purpose of the interview and upon consent, appointments were made to interview them at a convenient time.

A semi-structured interview guide was developed to collect the data. One of the advantages of the semi-structured interview was conversational flow as well as room for pursing and probing for further relevant information. ${ }^{[6]}$ The semi-structured interview guide had the following domains: (a) public understanding and perception of modern medicines/(b) sources of information pertaining to modern medicine and (c) treatment-seeking/medicineseeking behavior. The interview questions were pretested on six consumers to check the validity, reliability and accuracy as well as appropriateness of the questions. A brief semistructured interview guide is attached in Appendix 1.

The interviews were conducted in English and continued until the point of saturation when it was felt that no more new themes emerged. During the interviews, additional probing questions were asked to understand better the statements made by the interviewees. Demographic information comprised gender, age, race, and level of education, and occupation and marital status was also recorded. Interviews were transcribed into a written transcript and each written transcript was sent to the participants for verification. After the participants had verified the transcripts or had made the necessary amendments, the transcripts were then analyzed for thematic content.

\section{RESULTS}

Eighteen consumers (12 females and six males) participated in this study. Their age range varied from the early twenties to the late sixties. Out of 18, six were students. Education levels ranged from secondary school to higher level of education/university education.

Tables 1 and 2 depict statements and themes emerging from the qualitative interviews. 
Table 1: Key statements from interviews

\begin{tabular}{|c|c|}
\hline Broad categories & Statements \\
\hline $\begin{array}{l}\text { General views regarding } \\
\text { modern medicines/ } \\
\text { Characteristics of modern } \\
\text { medicines }\end{array}$ & $\begin{array}{l}\text { "Modern medicine looks more colorful as compared to herbs." (Respondent } 2 / \text { Age } 40 \text { ) } \\
\text { "Normally it is something in which there has been research done on it and after research; it is then formulated into a } \\
\text { medicine. ... After the medicine is formulated, the medicine is tested on animals first, before they "put it' on humans. } \\
\text { (Respondent 4/Age 45) } \\
\text { "Because when I take modern medicine, my problem not cures totally, after that it will come again." (Respondent 6/ } \\
\text { Age 35) } \\
\text { "Within half an hour after I took it (refers to tetracycline), my lips were smarting. There was a burning sensation and } \\
\text { itchy on my lips...I suppose I am personally allergic to tetracycline. Other people are taking tetracycline and nothing } \\
\text { happened to them. So you have to try it and find out about your allergies..." (Respondent 4/Age 45) } \\
\text { "I think the modern medicine is very good already compared to Chinese traditional medicine. Chinese medicine is } \\
\text { really bitter and smelly." (Respondent 10/Age 25) } \\
\text { "I suppose if you are taking tablets, maybe your condition is not so serious. If you are really given an intravenous } \\
\text { medicine or injection, that form of medication would indicate that the condition is more serious." (Respondent } 1 / \text { Age } 45 \text { ) }\end{array}$ \\
\hline $\begin{array}{l}\text { Information sources/ } \\
\text { information providers } \\
\text { regarding medicines }\end{array}$ & $\begin{array}{l}\text { "I will buy a lot of books. If I have something wrong with me I will search for books. They...If you have thyroid } \\
\text { problem you go and search for books pertaining to thyroid." (Respondent 15/Age 23) } \\
\text { "I used to read newspapers, I mean Sunday Star they used to come up with all these medicines and all that. I usually } \\
\text { look for the side-effects of the medicine that doctor prescribed for me." (Respondent 3/Age 20) } \\
\text { "Like gastric pain. I will ask my friend which medicine is better. Because there are many kinds of medicines for } \\
\text { gastric." (Respondent 2/Age 40) } \\
\text { "I will seek both pharmacists and doctors for that. Basically I will seek people who have studied about medicine or } \\
\text { these drugs." (Respondent 3/Age 20) }\end{array}$ \\
\hline $\begin{array}{l}\text { Medicine-taking/treatment- } \\
\text { seeking behavior }\end{array}$ & $\begin{array}{l}\text { "Normally I follow the instruction but sometimes I may forget to take. Sometimes I miss one or two doses, but is ok I } \\
\text { don't feel anything." (Respondent 16/Age 34) } \\
\text { I see...sometime my condition. If I feel good, I think I don't want to take the modern medicine again." (Respondent } \\
\text { 17/Age 19) }\end{array}$ \\
\hline
\end{tabular}

1. Characteristics of modern medicine/general views regarding medicines

(a) What are modern medicines?

Consumers viewed medicines as synthetically made and having undergone the process of research, testing and formulation. Some consumers also viewed modern medicine as unnatural.

"Modern medicine is something synthetic, not natural and... expensive." (Respondent 11/Age 22) "I go to Pharmacy. I buy lots of the medicine and keep it. When I need it, I just take it.” (Respondent 4/Age 45)

"Modern medicine as I know is most of them come from herbs. They extract it and then put into tablet/capsule something like that, it's not the pure herb, and some chemicals are added as well." (Respondent 3/Age 20)

(b) Combination of good/bad effects

Some people feel that modern medicine can cure illness while others have negative perceptions regarding medicines.

"I am comfortable with the effects of modern medicine...good effects...my pain and inflammation are usually relieved with modern medicine. For my gout condition...I took "zyloric pills" and it helped because it reduced my uric acid level." (Respondent 2/Age 40) "Like my friend having cancer, now already passed away. The modern medicine cannot heal him; the modern medicine needs to improve."
(Respondent 7/Age 55)

"The more serious cases, like cancer, after taking for a few months, the amounts of tablet need to add up, because the amounts already no use for them to control. This may cause 'dependence' on modern medicine." (Respondent 18/Age 25)

(c) Comparing traditional medicine with modern medicine

Some of the interviewees compared modern medicine with traditional medicine

"It can stop the diseases faster, compared with herbs that take time to cure the problem." (Respondent 2/ Age 40)

"Chinese medicine can cure, but Western (medicines) don't.” (Respondent 6/Age 35)

"Traditional medicine do not have side-effect, therefore I trusted the traditional medicine more modern medicine." (Respondent 9/Age 60)

(d) Factors affecting perception (Size/color)

Consumers' views indicated that the size, color and dosage form are strong determinants of the characteristics of medicine.

"Oh absolutely, I might be scared looking at the big-sized tablets you know, it looks scary.” (Respondent 12/Age 21)

"Older people (adult) like me never care about color, unless it looks abnormal. Like tablet, usually white color but if I see suddenly change to black color, purple then I won't take it..." (Respondent 13/Age 60) 
Table 2: Key themes from interviews

\begin{tabular}{|c|c|c|c|}
\hline Main themes & Correctly identified themes & $\begin{array}{l}\text { Misconceptions (Need education and } \\
\text { information) }\end{array}$ & Perceptions/opinions \\
\hline $\begin{array}{l}\text { General views regarding modern } \\
\text { medicines/Characteristics of modern } \\
\text { medicine }\end{array}$ & $\begin{array}{l}\text { If you are given tablet, } \\
\text { the condition is minor, if } \\
\text { injection then the condition } \\
\text { is serious. } \\
\text { Modern medicines are often } \\
\text { chemically synthesized. }\end{array}$ & $\begin{array}{l}\text { All drugs can cause "dependence". } \\
\text { You have to experiment, take the } \\
\text { medicine and find out your allergy. } \\
\text { Chinese medicines cure while Western } \\
\text { medicines do not. } \\
\text { Chinese medicine has no side-effects. } \\
\text { Modern medicines are dangerous. }\end{array}$ & $\begin{array}{l}\text { Big tablets look scary. } \\
\text { If there is a sudden change in color } \\
\text { such as "black and purple" then } \\
\text { would not take it. } \\
\text { Red and yellow tablets considered } \\
\text { "sweet". } \\
\text { White tablet is considered "bitter". }\end{array}$ \\
\hline Information sources regarding medicines & Doctors and pharmacists & $\begin{array}{l}\text { "Self-reading of drug information" and } \\
\text { looking for more side-effects. } \\
\text { Compare and contrast different drug } \\
\text { information sources and then "decide". } \\
\text { Search from medical books, if you have } \\
\text { thyroid problem. } \\
\text { Internet } \\
\text { Newspapers, "Sunday Star". }\end{array}$ & $\begin{array}{l}\text { Doctors and my parents. } \\
\text { Doctors are more expert in } \\
\text { providing drug information. } \\
\text { Friends (gastric pain). } \\
\text { Website introduced by doctors. } \\
\text { Medicine leaflets are useful. } \\
\text { Family }\end{array}$ \\
\hline Medicine-taking behavior & $\begin{array}{l}\text { Many consumers complied } \\
\text { with "medicine-taking } \\
\text { instructions". }\end{array}$ & $\begin{array}{l}\text { Antibiotics were taken properly while } \\
\text { other drugs are not } \\
\text { Missing one or two doses alright, it } \\
\text { would not harm. } \\
\text { Stop taking a medicine if you are fine. } \\
\text { Immediately do not take high dose of a } \\
\text { medicine. }\end{array}$ & \\
\hline Treatment-seeking behavior & $\begin{array}{l}\text { If you have cold and flu, take } \\
\text { garlic, Vitamin } \mathrm{C} \text { and rest }\end{array}$ & $\begin{array}{l}\text { Only see the doctor if it is "free } \\
\text { consultation". } \\
\text { Before I seek the doctor's opinion, } \\
\text { I will give my body a few days to build } \\
\text { antibodies. }\end{array}$ & $\begin{array}{l}\text { Medicated oil. } \\
\text { Use Chinese medicines if there is a } \\
\text { minor illness. }\end{array}$ \\
\hline
\end{tabular}

"When I was a child, when I looked at the medicine, normally the red, yellow color tablets will have the sweet color...the white-colored tablets will give me the image that they are very bitter. When I grew up, I took the white color gastric tablet, I have the image that it might be bitter, but when I tasted it, it had the taste like menthol. In different age, we have different thinking." (Respondent 14/Age 65)

2. Source of drug information and information providers

(a) Sources of drug information

Many respondents looked on the internet for information on medicines, while others relied on books and newspapers.

"Of course yes...to make sure the medicines taken have no side-effects. I'll search through the net, mostly through internet." (Respondent 6/Age 35) "... when doctor gives medication, I used to... check in the internet what are the side-effects. Usually I will go for the side-effects rather than the goodness. I'm very concerned about the sideeffects. So scared you know..." (Respondent 3/ Age 20)

(b) Drug information providers

"...The doctor because they are more experienced... I feel more confident with the doctors." (Respondent 16/Age 34)

“...I mean, when I just want to know information about a drug, I will just try to read up and I will try to compare the different sources of information to see whether they are giving the same information, instead of contradictory information. If they are the same, then the information has to be true..." (Respondent 4/Age 45)

A few of the interviewees found that information leaflets were helpful.

"...so from the leaflets you can know which dosage is more suitable for you. Like panadol there are lots of dosages... panadol menstrual. The information will let you know how to differentiate. Just the common information, it is not so detail. But I think for layman is enough.” (Respondent 2/Age 40)

3. Medicine-taking and treatment-seeking behavior

(a) Medicine-taking behavior

Some respondents complied with the medicine use instructions while others did not follow.

"...If they ask me to take an antibiotic three times per day, I will divide the hours per day by three and take it every eight hours. I would even wake up at night to take the antibiotic at the exact time. I am very particular about that." (Respondent 4/Age 45) "I will only finish the antibiotic. Other medication I will stop taking after the symptoms have resolved, because if the sickness was healed 
already there are no need for the medication." (Respondent 16/Age 34)

(b) Treatment-seeking behavior

"Yes, but before I seek the doctor's attention, I will give a few days for my body to build up antibodies to fight the sickness. After a few days, if can't be cured, then only I will see a doctor." (Respondent 5/Age 25)

"I'll go to see doctor. I'm in the factory, because it is free. But if in my home, if the sickness is like fever or running nose, usually I won't see doctor. I'll take "Panadol" and try whether I can recover or not. If really cannot, then only I'll consult the doctor..." (Respondent 18/Age 25).

\section{DISCUSSION}

Tables 1 and 2 show different themes emerging from qualitative interviews. The themes showed varied opinions, one group perceived modern medicine as "beneficial" while the others have "negative views" towards medicines. Previous studies have also shown mixed trends; some have a fairly negative view of medicines, perceiving them to be generally harmful substances over-prescribed by doctors, ${ }^{[7-9]}$ while a study in Sweden highlighted "positive perception regarding medicine. ${ }^{[10]}$

The participants stated traditional medicine as "natural" and safer, which is fine up to some extent, however, the worrying part was the assumption that traditional Chinese medicines (TCMs) have no side-effects and TCMs can cure while Western medicines don't. These beliefs are in line with an earlier study which states that the patients who regularly use herbal medicine were more likely to perceive "modern medicines" as harmful substances. ${ }^{[7-9]}$ As TCMs are widely used in Malaysia, there is a need to inform and educate the public regarding their potential advantages and harmful effects. Another misconception which needed correction and education is that "all drugs including anticancers" can cause "dependence".

A few themes were correctly identified such as that "tablets" are generally used for "non-acute conditions" while injection for "serious conditions". Another interesting aspect in our study was the perception regarding color. Respondents associated red and yellow with "sweet" while purple and black were considered as "non-appealing" depicting that these colors could lead to non-compliance. Another study ${ }^{[1]}$ found that red, yellow and orange had a stimulant effect while blue and green are related to tranquilizing effects.

Many consumers correctly identified doctors and pharmacist as sources of drug information and relied on the health professionals' advice and suggestion while others looked for friends, internet, newspapers and books. Although there is a question mark regarding the reliability of drug information, many people were interested in checking the information on the internet. Also, many consumers were just concerned with the side-effects of a medicine-as every drug has some side-effects, this approach could create misunderstanding about the issues.

A few participants mentioned that they are "searching drug information" from websites recommended by/for doctors or pharmacists, however it was unclear whether these websites were designed for healthcare professionals or for consumers. We felt that there is a lot of grey area and many "misconceptions" regarding "medicine information-seeking behavior" demanding further research and community education on the issue.

Many consumers exactly followed their doctors' instructions on how to take medicines; however a few consumers reported that they stop taking medicines once the symptoms have been resolved. Patient compliance is strongly related to perceptions of the necessity of medication. ${ }^{[8]}$ In previous studies, it has been observed that consumers were reluctant to take the drug even though they knew that they needed to take the medicine to cure the disease. ${ }^{[12,13]}$ In the present study we have observed that in many cases consumers do not mind missing a few doses of a medicine. The Malaysian government is spending more than 1 billion RM (Malaysian Ringitt) to subsidize pharmaceuticals in public hospitals, however, if the medicines are not used properly, then this could lead to poor compliance as well as "poor value for money".

Many consumers in the present study were getting information from the media and some of them overly emphasized the "adverse effects". Moreover, the inadequate information provided by health professionals and adverse effects with the medicine could be the reasons influencing consumers' medicine use behavior. ${ }^{[11,12]}$ As a large number of people rely on the internet to get drug information, and the internet also supports the view "to try alternative medicine", hence influencing consumers' medicine-taking behavior. ${ }^{[14]}$

There is evidence that the participants' occasional meeting with the pharmacist generated a positive attitude towards medicines ${ }^{[10]}$ hence there is a need to involve more pharmacists, doctors and organize public health campaigns around the issue. Compliance is a well-documented problem in Malaysia and a previous study suggests that there is a need for health education programs so that better compliance could be achieved. ${ }^{[15]}$

Journal of Young Pharmacists Vol 4 / No 2 


\section{Appendix 1: Semi-structured interview guide}

1 Demographic data (Gender, age, race, level of education, occupation, income, marital status

2 The Public's Understanding and Perception of Modern Medicine/Characteristics of modern medicine

a) Do you know what modern medicine is?

b) When you hear the term 'modern medicine', what images or thoughts come to your mind?

c) What do you believe drugs are able to do to people?

d) Modern medicine comes in various forms like injectables, tablets, capsules, suppositories, syrup, suspension, etc. Does the appearance of medicine affect your perception regarding modern medicine?

e) Does the color of the medicine affect your perception regarding modern medicine?

f) What are your main concerns when you are prescribed or dispensed with a modern medicine?

3 The sources of information regarding modern medicine

a) Have you ever received any information pertaining to a modern medicine?

b) Who do you usually approach to obtain some information pertaining to modern medicine?

c) Have you ever tried looking for information on your own? (If yes, what are the sources of your information?)

d) What sources of information do you usually trust?

$4 \quad$ Medicine/Treatment-seeking behavior

a) When you are feeling ill (for instance, you are having a common cold, experiencing pain or having a headache), what do you normally do?

b) If you are in need of modern medicine, where do you usually go to get your supply of medicine?

c) What are the modern medicines you have taken in the past and why did you take those medicines?

d) When you recall about your experiences with modern medicine, what are the thoughts you have on modern medicine?

e) Have you ever seen or heard of other people's experienced effects after they had taken their medication (modern medicine)?

f) Does your prescriber or dispenser usually explain to you how to use the medicine? If yes, do you usually follow the directions suggested to you by your prescriber or dispenser?

g) Have you ever adjusted the way of taking medication so that it is suitable for you? If yes, why do you make such adjustments?

Concluding questions

Do you have any additional points you would like to add pertaining to this topic?

\section{Limitations of the study}

The study was only conducted in Penang which may affect its generalization to other parts of Malaysia. Only Englishspeaking consumers were interviewed and as their level of knowledge could be better than non-educated people, it is difficult to say that all issues have been identified. Nevertheless, the study unearthed some crucial information gaps and shed light on vital medicine use issues in Malaysia.

\section{CONCLUSION}

Consumers' understanding regarding modern medicine varied, ranging from accurate information to misleading and incorrect information. Various gaps were identified in the consumers' approach to seek medicine information. Traditional medicine was considered harmless and it was found out that dosage form and medicine color could affect consumers' medicine-seeking and use behaviors. Corrective actions could be to create "consumers' medicine information sources", build public health campaigns as well as to conduct empirical research on these issues.

\section{REFERENCES}

1. National Cancer Institute. US National Institute of Health. Available from: http://www.cancer.gov/templates/db_alpha.aspx?CdrID = 454743. [Last accessed on 2011 May 25].

2. Haak H. Pharmaceuticals in two Brazilian villages: Lay practices and perceptions. Soc Sci Med 1988;27:1415-27.
3. Bjornsdottir I, Almarsdottir AB, Traulsen JM. The lay public's explicit and implicit definitions of drugs. Res Social Adm Pharm 2009;5:40-50.

4. Brieger WR, Salami KK, Oshiname FO. Perceptions of drug color among drug sellers and consumers in rural southwestern Nigeria. Res Social Adm Pharm 2007;3:303e-319.

5. Goh A1, Faridah A, Rosminah MD, Nour Hanah O, Noor Aini Z. Expenditure on Medicines in Malaysia: Estimates from Malaysian Statistics on Medicines 2005. $7^{\text {th }}$ MOH-AAM Scientific Meeting, 2007.

6. Green J, Thorogood N. Qualitative Methods for Health Research. $1^{\text {st }}$ ed. London: Sage Publications Ltd.; 2004. p. 1-200.

7. Horne R, Weinman J. Patients' beliefs about prescribed medicines and their role in adherence to treatment in chronic physical illness. J Psychosom Res 1999;47:555-67.

8. Horne R, Coombes I, Davies G, Hankins M, Vincent R. Barriers to optimum management of heart failure by general practitioners. Br J Gen Pract 1999;49:353-7.

9. Horne R, Weinman J, Hankins M. The Beliefs about Medicines Questionnaire (BMQ): A new method for assessing cognitive representations of medication. Psychol Health 1999;10:1-29.

10. Isacson D, Bingefors K. Attitudes towards drugs - A survey in the general population. Pharm World Sci 2002;24:104-10.

11. Asscher AW, Parr GD, Whitmarsh VB. Education and debate: Towards the safer use of medicines. Br Med J 1995;311:1003-5.

12. Britten N. Patients' ideas about medicines: A qualitative study in a general practive population. Br J Gen Pract 1994;44:465-8.

13. Townsend A, Hunt K, Wyke S. Managing multiple morbidity in mid-life: A qualitative study of attitudes to drug use. Br Med J 2003;327:837.

14. Wathen CN, Harris RM. An examination of the health information seeking experiences of women in rural Ontario, Canada. Information Research 2006;11:267. [Available from: http://www.InformationR.net/ir/11-4/ paper267.html]. [Last accessed on 2011 May 25].

15. Naing NN, Catherine D, Isa AR, Rosemi S, Noraini B, Mahmod MR. Factors contributing to poor compliance with anti-TB treatment among tuberculosis patients. Southeast Asian J Trop Med Public Health 2001;32:369-82.

How to cite this article: Babar Z, Hassali MA, Shyong TL, Hin TK, Cien CS, Bin LS, et al. An evaluation of consumers' perceptions regarding "modern medicines" in Penang, Malaysia. J Young Pharmacists 2012;4:108-13.

Source of Support: Nil, Conflict of Interest: None declared. 